\title{
Breast milk sodium concentration, sodium intake and weight loss in breast-feeding newborn infants
}

\author{
Rosa Manganaro ${ }^{1}$, Lucia Marseglia ${ }^{1}$, Carmelo Mamì ${ }^{1}$, Antonella Palmara ${ }^{1}$, Antonina Paolata ${ }^{1}$, \\ Saverio Loddo ${ }^{2}$, Romana Gargano ${ }^{3}$, Maurizio Mondello ${ }^{3}$ and Marina Gemelli ${ }^{1 *}$ \\ ${ }^{1}$ Department of Paediatric and Surgery Sciences, University of Messina, 98100 Messina, Italy \\ ${ }^{2}$ Department of Experimental Pathology and Microbiology, University of Messina, 98100 Messina, Italy \\ ${ }^{3}$ Department of Statistics, University of Messina, 98100 Messina, Italy
}

(Received 22 March 2006 - Revised 17 July 2006 - Accepted 15 August 2006)

\begin{abstract}
Elevated breast milk (BM) Na concentration is regarded as responsible for elevated Na intake. To verify the clinical significance of milk Na concentration, we studied the relationship between $\mathrm{BM} \mathrm{Na}{ }^{+}$concentration and infants' daily $\mathrm{Na}^{+}$intake, infants' daily BM intake (DBMI) and percentage weight loss (\%WL) in healthy newborn infants. All mothers who gave birth to a single healthy infant, between February and March 2004 at the Obstetric Clinic of University of Messina (Italy), were invited to participate if they were willing to attempt to breastfeed exclusively. BM $\mathrm{Na}^{+}$concentration, DBMI, $\mathrm{Na}^{+}$intake and \%WL were determined on the third day after delivery. Statistical analysis was performed by Spearman's correlation test, classification and regression trees and the generalised linear model. Of the 270 eligible mothers, 208 participated in the study. The results showed that on the third day postpartum $\mathrm{BM} \mathrm{Na}^{+}$concentration was 23.05 (SD 1.10) mmol/l, mean DBMI was 202 (SD 68.9) g/d, and mean $\mathrm{Na}^{+}$intake was $4.36(\mathrm{SD} 0.22) \mathrm{mmol} / \mathrm{d}$ and $1.36(\mathrm{SD} 0.07) \mathrm{mmol} / \mathrm{kg}$ per d. BM Na${ }^{+}$concentration was inversely related to infant DBMI, and $\mathrm{Na}^{+}$intake was directly related to infant DBMI and not to BM Na${ }^{+}$concentration. \%WL was significantly correlated only to DBMI. In conclusion, the present data demonstrate, for the first time, that when lactogenesis is suboptimal, $\mathrm{BM} \mathrm{Na}^{+}$concentration is higher, but infants' $\mathrm{Na}^{+}$intake is lower. Finally, the present data probably suggest that for the clinical assessment of breast-feeding, evaluation of milk intake remains the best method.
\end{abstract}

Breast milk sodium: Infant sodium intake: Infant weight loss

Breast milk (BM) is widely advocated as the optimal nutrient for infants. Furthermore, in the last few years an increased number of reports have emphasised that failure of breast-feeding can sometimes result in dehydration and poor weight gain, with serious complications such as severe hypernatraemic dehydration, seizures, and permanent neurological and embolic damage (Arboit \& Gildengers, 1980; Rowland et al. 1982; Clarke \& Sibert, 1985; Cooper et al. 1995; Oddie et al. 2001; Livingstone et al. 2000). We have reported that during the first days of life, $7.7 \%$ of exclusively breast-fed healthy, term newborn infants present a weight loss exceeding $10 \%$ and, in $35 \%$ of these, also hypernatraemia occurs (Manganaro et al. 2001).

Some authors, in noting a high $\mathrm{BM} \mathrm{Na}^{+}$concentration in the mothers of breast-feeding infants presenting with hypernatraemic dehydration, have suggested a causal relationship between the infants' hypernatraemia and high $\mathrm{BM} \mathrm{Na}^{+}$concentration, and have advocated the cessation of breast-feeding (Peters, 1989; Kumral et al. 2002).

The objective of the present study was to examine, in a population of healthy, exclusively breast-fed, newborn infants on the third day of life, the relationship between infants' daily $\mathrm{BM}$ intake (DBMI), daily $\mathrm{Na}$ intake, and percentage weight loss (\%WL) and $\mathrm{BM} \mathrm{Na}^{+}$concentration.

\section{Subjects and methods}

After informed consent of mothers, and approval of the ethics committee of our hospital, all mothers, who gave birth between February and March 2004 at the Obstetric Clinic of University of Messina, and their babies were recruited for the study if they met the selection criteria. The criteria were: (a) uncomplicated prenatal course; (b) lack of maternal major medical problems and/or chronic medication; (c) single infant with a gestational age equal to or higher than 34 weeks, an Apgar score of more than 8 at 5 min, no congenital malformation, normal neonatal adaptation, and exclusively breastfed; (d) hospital discharge after day 3. Information on the mother (age, parity, mode of delivery, any pathological condition, breast-feeding history, and level of education) and on the neonate (gestational age, mode of delivery, Apgar score, weight at birth, clinical examination, observation of breastfeeding, daily control of weight, \%WL, and laboratory test results when performed) was recorded. All neonates were rooming in and were nursed by their mothers. Breast-feeding was encouraged by the baby being put to the breast by healthcare staff. All neonates were initially put to the breast in the delivery room within $1 \mathrm{~h}$ of life and subsequently on

\footnotetext{
Abbreviations: BM, breast milk; DBMI, daily breast milk intake; \%WL, percentage weight loss.

* Corresponding author: Professor Marina Gemelli, fax + 39090 2212150, email Marina.Gemelli@unime.it
} 
demand in the mother's room $24 \mathrm{hperd}$ (eight to ten feeds perd). No infant received glucose or formula during the first $3 \mathrm{~d}$ of life. A milk sample was obtained from all mothers by manual expression from a single breast on the third day postpartum, between 09.00 and 11.00 hours, to minimise the effects of diurnal variations. On the third day of life, DBMI was measured by test weighing, corrected for insensible water loss by infants during the feed, which is a validated measure of milk intake (Neville, 1987). All neonates were weighed fully clothed, immediately before and after each suckling episode, throughout $24 \mathrm{~h}$, on an identical calibrated electronic scale equipped with an infant seat.

\section{Analysis of mothers' milk}

The milk samples were collected into sterile plastic containers. Due to the large variation in lipid content, and the potential for fatty samples to result in a falsely low $\mathrm{Na}^{+}$concentration assessment, the milk samples were immediately sampled into $12 \times 75$ polystyrene tubes and centrifuged at $3000 \mathrm{rpm}$ for $10 \mathrm{~min}$ at $4^{\circ} \mathrm{C}$. Then, those liquid layers that were free of lipid were frozen and stored at $-35^{\circ} \mathrm{C}$. Analysis of $\mathrm{Na}$ was performed by a flame photometer IL943 (Instrumentation Laboratory, Lexington, MA, USA).

The $\mathrm{BM} \mathrm{Na}^{+}$concentrations are expressed as $\mathrm{mmol} / \mathrm{l}$. $\mathrm{Na}^{+}$ intake ( $\mathrm{mmol} / \mathrm{d}$ and $\mathrm{mol} / \mathrm{kg}$ per d) on the third day of life was calculated.

\section{Statistical analysis}

Preliminary analyses were performed by Spearman's correlation test in order to describe the relationships between the variables regarding the information on mothers and on neonates and $\mathrm{BM} \mathrm{Na}{ }^{+}$concentration, $\mathrm{Na}^{+}$intake (mmol/d), $\mathrm{Na}^{+}$intake (mmol/kg perd) and \%WL.

To verify the relationship between $\mathrm{BM} \mathrm{Na}^{+}$concentration, $\mathrm{Na}^{+}$intake perd, and $\mathrm{Na}^{+}$intake perkg perd $v$. DBMI and $\% \mathrm{WL}$, we performed regression tree analysis (Breiman et al. 1984). The central thrust of tree-based methods is the extraction of subgroups of observations. A simple tree consists of a main node (root) and several daughter nodes, which are subgroups. A node cannot have more than two nodes according to recursive portioning methods. The analysis of the results obtained with the 'classification and regression tree' (McCullagh \& Nelder, 1999) approach has led us to try to identify a possible dependence between $\mathrm{BM} \mathrm{Na}{ }^{+}$concentration, $\mathrm{Na}^{+}$ intake per $\mathrm{d}, \mathrm{Na}^{+}$intake per kg perd, and DBMI and \%WL. For this reason, we have executed the generalised linear model and have applied a logarithm transformation to the outcome variables to make our distribution linear. All statistical analyses were performed by R statistical software (R Development core team, Vienna, Austria).

\section{Results}

In total, 270 mothers gave birth during the recruitment period. Of these, 208 who satisfied selection criteria were enrolled in the study. As only five of the 208 infants were preterm, our population was considered as being homogeneous. The characteristics of the 208 mother-infant pairs are shown in Table 1. $\mathrm{BM} \mathrm{Na}{ }^{+}$concentration, and infants' DBMI, $\mathrm{Na}^{+}$intake per $\mathrm{d}$,
Table 1. Characteristics of 208 mother-infant pairs

(Mean values, standard deviations and 95\% confidence intervals)

\begin{tabular}{|c|c|c|c|}
\hline & Mean & SD & $95 \% \mathrm{Cl}$ \\
\hline Birth weight $(\mathrm{kg})$ & 3.195 & 0.435 & $3.108,3 \cdot 281$ \\
\hline Gestational age (weeks) & 38.4 & 1.3 & $38 \cdot 2,38 \cdot 6$ \\
\hline Weight loss (\%) & $6 \cdot 7$ & 1.6 & $6 \cdot 4,7 \cdot 0$ \\
\hline Maternal age (years) & 29.8 & 4.6 & $28 \cdot 8,30 \cdot 7$ \\
\hline
\end{tabular}

and $\mathrm{Na}^{+}$intake per $\mathrm{kg}$ per $\mathrm{d}$ on the third day after delivery are reported in Table 2. The Spearman's correlation test shows a significant inverse relationship between $\mathrm{BM} \mathrm{Na}^{+}$concentration and DBMI $(\rho-0.283 ; P=0.003)$, and between $\% \mathrm{WL}$ and DBMI ( $\rho-0.258 ; P=0.004)$. Also, on the contrary, the Spearman's correlation test shows a positive association between $\mathrm{Na}^{+}$ intake per $d$ and DBMI $(\rho 0.441 ; P=0.000)$ and between $\mathrm{Na}^{+}$ intake perkg perd and DBMI $(\rho 0.329 ; P=0.001)$. The plots of these relationships are shown in Fig. 1. Figs. 2, 3 and 4 report the regression trees, where the average of the response variables are indicated into the circles for subgroups or into the rectangles for the terminal nodes of the single group. To avoid the trees reaching enormous size, we have coded predictor variable into four levels in an ordinal scale. Fig. 2 shows the relationship between the three response variables $\mathrm{BM} \mathrm{Na}^{+}$concentration, $\mathrm{Na}^{+}$intake per $\mathrm{d}$, and $\mathrm{Na}^{+}$intake per $\mathrm{kg}$ per $\mathrm{d}$, and the predictor variable DBMI. Fig. 2 (a) shows that for a higher level of DBMI, the $\mathrm{BM} \mathrm{Na}^{+}$concentration is lower, and vice versa; Figs. 2 (b) and (c) show the positive relationship between the response variables $\mathrm{Na}^{+}$intake per $\mathrm{d}$ and $\mathrm{Na}^{+}$intake per kg per $\mathrm{d}$ and the predictor variable DBMI. Figs. 3 and 4 show the relationships between the predictor variable \%WL and the response variables $\mathrm{BM} \mathrm{Na}^{+}$concentration, $\mathrm{Na}^{+}$intake per $\mathrm{d}, \mathrm{Na}^{+}$intake perkg perd, and DBMI. The results suggest a possible dependence only for DBMI and \%WL (Fig. 4 (b)).

The analysis of the results, obtained with Spearman's correlation test and the classification and regression tree approach, has shown a possible dependence between $\mathrm{BM} \mathrm{Na}^{+}$concentration, $\mathrm{Na}^{+}$intake perd, $\mathrm{Na}^{+}$intake perkg perd, DBMI and $\%$ WL. For this reason, we performed the generalised linear model. We have applied a logarithm transformation to the outcome variables to make our distribution linear in order to obtain residuals more close to a Gaussian distribution. Table 3 shows the results for the fit models for each outcome variable, and Fig. 5 shows the plots of relationships between these variables for the fit models. Analysing them, we deduce the existence of an inverse relationship between $\mathrm{BM} \mathrm{Na}^{+}$concentration and infants' DBMI (for each unitary increase in infants' DBMI, $\mathrm{BM} \mathrm{Na}^{+}$concentration decreases by a mean of 0.997). By contrast, the relationship between $\mathrm{Na}^{+}$intake per $\mathrm{d}$

Table 2. Breast milk (BM) sodium concentration and infant daily sodium intake

(Mean values, standard deviations and $95 \%$ confidence intervals)

\begin{tabular}{lrrc}
\hline & Mean & SD & $95 \% \mathrm{Cl}$ \\
\hline $\mathrm{BM} \mathrm{Na}^{+}$concentration (mmol/l) & 23.05 & 1.10 & $20.87,25.24$ \\
$\mathrm{Na}^{+}$intake (mmol/d) & 4.36 & 0.22 & $3.93,4.81$ \\
$\mathrm{Na}^{+}$intake (mmol/kg per d) & 1.36 & 0.07 & $1.22,1.51$ \\
\hline
\end{tabular}



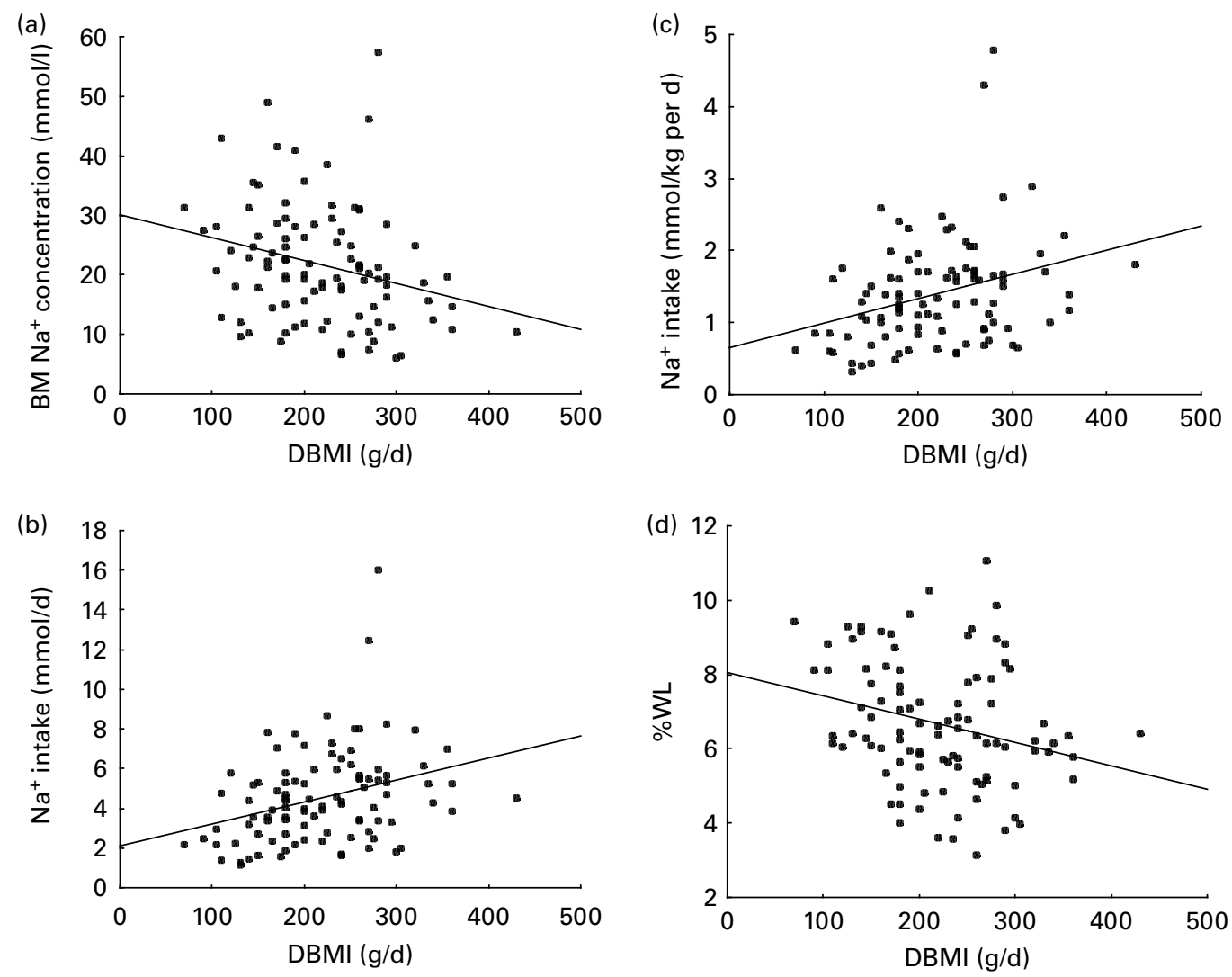

Fig. 1. Relationships with daily breast milk intake (DBMI). (a) Relationship between breast milk (BM) $\mathrm{Na}^{+}$concentration and DBMI $(\rho-0.283 ; P=0.003)$; (b) relationship between daily $\mathrm{Na}^{+}$intake (mmol/d) and DBMI ( $\left.\rho 0.441 ; P=0.000\right)$; (c) relationship between daily $\mathrm{Na}^{+}$intake $(\mathrm{mmol} / \mathrm{kg} \mathrm{per} d)$ and DBMI $(\rho 0.329$; $P=0.001)$; (d) relationship between percentage weight loss (\%WL) and DBMI $(\rho-0.258 ; P=0.004)$.

and $\mathrm{Na}^{+}$intake perkg perd, and infants' DBMI is positive (for each unitary increase in infants' DBMI, the dependent variables increase, for both, by a mean of 1.002).

\section{Discussion}

It has long been known that after parturition the abrupt changes in plasma concentrations of the hormones of pregnancy trigger the onset of milk secretion, defined as lactogenesis stage II, which take place during the first $4 \mathrm{~d}$ postpartum and involving a programmed set of changes in milk composition and volumes (Neville \& Morton, 2001; Neville et al. 2001). In particular, immediately after birth there begins a fall in BM Na and chloride concentrations, which is largely complete by $72 \mathrm{~h}$ postpartum (Neville et al. 1991). These changes precede the onset of the large increase in milk volume and are explained by closure of the tight junctions that block the paracellular pathway (Chen et al. 1998; Nguyen \& Neville, 1998). A delay in the onset of
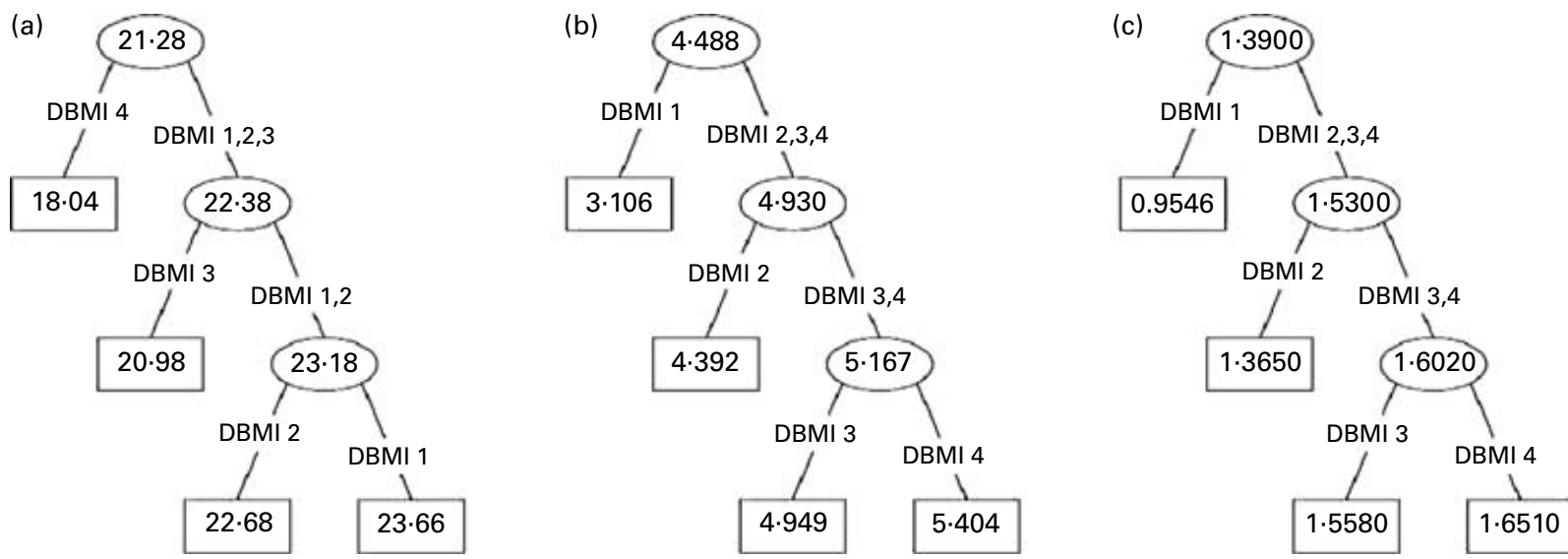

Fig. 2. Regression trees showing relationships between breast milk (BM) $\mathrm{Na}^{+}$concentration and daily $\mathrm{BM}$ intake (DBMI) (a), $\mathrm{Na}^{+}$intake (mmol/kg perd) and DBMI (b) and $\mathrm{Na}^{+}$intake (mmol/d) and DBMI (c). DBMI 1, intake $<180 \mathrm{~g} / \mathrm{d}$; DBMI 2, intake $\geq 180$ to $<220 \mathrm{~g} / \mathrm{d}$; DBMI 3 , intake $\geq 220$ to $<267.5 \mathrm{~g} / \mathrm{d}$, DBMI 4 , intake $\geq 267.5 \mathrm{~g} / \mathrm{d}$. 

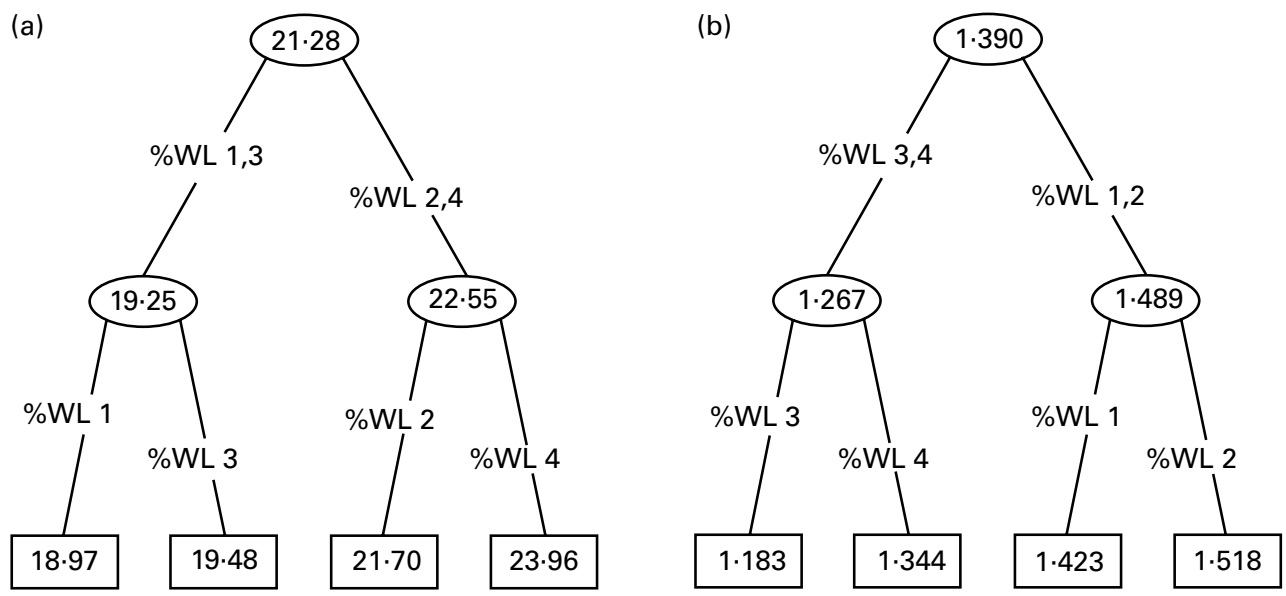

Fig. 3. Regression trees showing relationships between breast milk $\mathrm{Na}^{+}$concentration and percentage weight loss (\%WL) (a) and $\mathrm{Na}^{+}$intake (mmol/kg per d) and $\% W L$ (b). \%WL $1, W L \leq 5 \%$; $\%$ WL $2, W L>5$ to $\leq 6.5 \%$; \%WL 3 , WL $>6.5$ to $\leq 8 \%$; \%WL 4 , WL $>8 \%$.
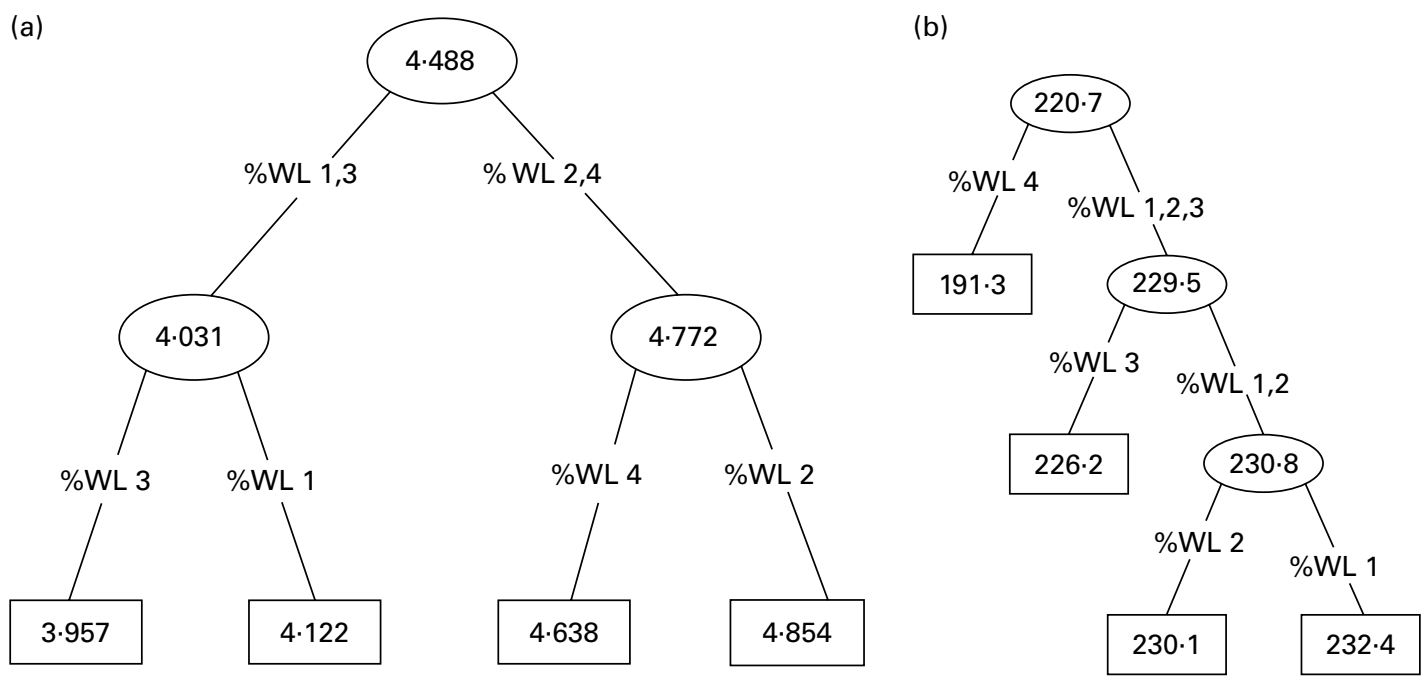

Fig. 4. Regression trees showing relationships between $\mathrm{Na}^{+}$intake (mmol/d) and percentage weight loss (\%WL) (a) and daily breast milk intake and \%WL (b). $\% \mathrm{WL} 1, \mathrm{WL} \leq 5 \%$; $\% \mathrm{WL} 2$, WL $>5$ to $\leq 6.5 \% ; \% \mathrm{WL} 3, \mathrm{WL}>6.5$ to $\leq 8 \% ; \% \mathrm{WL} 4, \mathrm{WL}>8 \%$.

Table 3. Report of generalised linear model for breast milk (BM) sodium concentration, infant daily sodium intake $v$. daily BM intake (DBMI) (Coefficients, $t$ values and standard errors)

\begin{tabular}{llrrrc}
\hline & & Coefficient & \multicolumn{1}{c}{$t$} & SE & $P$ \\
\hline $\mathrm{BM} \mathrm{Na}^{+}$concentration & Intercept & 3.349 & 21.343 & 0.159 & 0.000 \\
& DBMI & -0.002 & -2.904 & 0.000 & 0.004 \\
$\mathrm{Na}^{+}$intake perd & Intercept & 0.740 & 4.453 & 0.166 & 0.000 \\
\multirow{2}{*}{$\mathrm{Na}^{+}$intake per kg perd } & DBMI & 0.002 & 3.994 & 0.000 & 0.000 \\
& Intercept & -0.426 & -2.547 & 0.167 & 0.012 \\
& DBMI & 0.002 & 0.000 & 3.907 & 0.000 \\
\hline
\end{tabular}

lactogenesis has been reported with poorly controlled diabetes (Hartmann \& Cregan, 2001) and stress during parturition (Dewey et al. 2003; Evans et al. 2003) and it has been also correlated with high $\mathrm{BM} \mathrm{Na}^{+}$concentration in poorly nursed infants (Rand \& Kolberg, 2001). Moreover, some authors, in noting a relationship between neonatal hypernatraemic dehydration and elevated $\mathrm{BM} \mathrm{Na}{ }^{+}$concentration, have suggested a direct causal relationship, but they have placed little emphasis on evaluating the volume of BM intake (Oddie et al. 2001; Rand \& Kolberg, 2001; Kumral et al. 2002).

We in 208 mother-infant pairs found that on the third day postpartum the mean $\mathrm{BM} \mathrm{Na}{ }^{+}$concentration was 23.05 
(a)

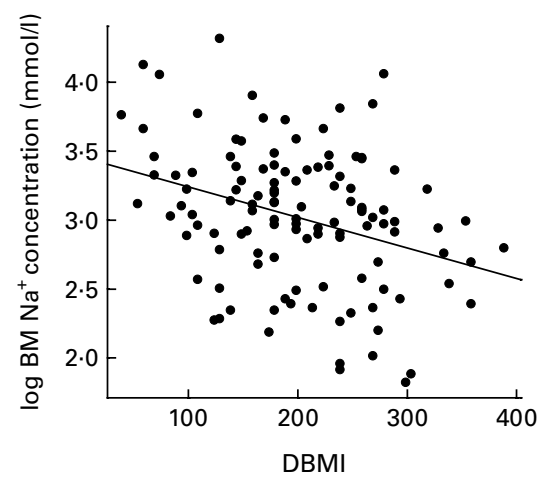

(b)

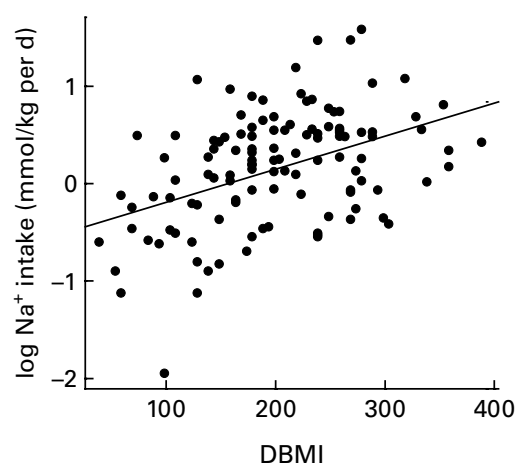

(c)

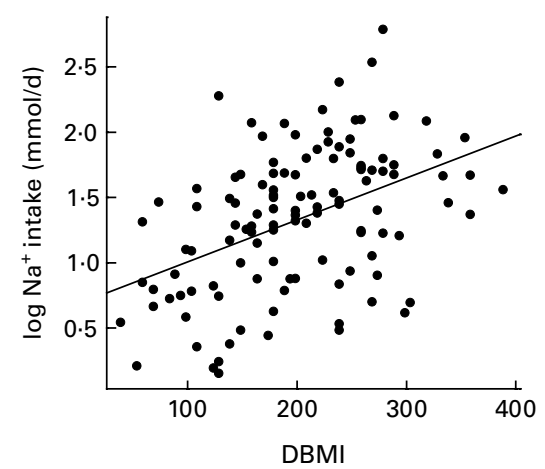

Fig. 5. Plot of response $v$. fit between breast milk (BM) $\mathrm{Na}^{+}$concentration (a), $\mathrm{Na}^{+}$intake (mmol/kg per d) (b) and $\mathrm{Na}^{+}$intake (mmol/d) (c) $v$. daily BM intake (DBMI).

(SD 1.10) mmol/l, and the mean DBMI was 202 (SD 68.9) g/d. The BM Na${ }^{+}$concentration was inversely related to infants' DBMI, and decreased, by a mean of 0.997 , for every unitary increase of DBMI. The mean infants' $\mathrm{Na}^{+}$intake was, respectively, 4.36 (SD 0.22) $\mathrm{mmol} / \mathrm{d}$ and 1.36 (SD 0.07) $\mathrm{mmol} /$ kg perd. $\mathrm{Na}^{+}$intake was directly related to infants' DBMI and not to $\mathrm{BM} \mathrm{Na}{ }^{+}$concentration. Moreover, we found that only infants' DBMI presents a relationship with infant weight loss. The present data confirm that high $\mathrm{BM} \mathrm{Na}^{+}$concentration is only a marker of suboptimal lactogenesis, which can be determined by a delay in the onset of lactogenesis or secondary to poor breast-feeding technique. Moreover, our finding that infants' DBMI is inversely related to $\mathrm{BM} \mathrm{Na}{ }^{+}$ concentration and positively related to infants' $\mathrm{Na}^{+}$intake, for the first time, demonstrates that when lactogenesis is suboptimal, $\mathrm{BM} \mathrm{Na}{ }^{+}$concentration is higher, but infants' $\mathrm{Na}^{+}$ intake is lower. These data support the hypothesis that, in breast-feeding infants, hypernatraemic dehydration, when it occurs, probably is the direct result of low feeding and not of increased $\mathrm{BM} \mathrm{Na}{ }^{+}$concentration (Rand \& Kolberg, 2001; Richmond, 2003).

In conclusion, the present data clearly confirm that, in the assessment of breast-feeding, a high concentration of BM $\mathrm{Na}^{+}$concentration may be predictive of impending lactation failure but it is not an indication to interrupt breast-feeding. Moreover, the data suggest that for the clinical assessment of breast-feeding, evaluation of milk intake, for its ease and reliability, remains the best method.

\section{References}

Arboit JM \& Gildengers E (1980) Breastfeeding and hypernatremia. J Pediatr 97, 335-336.

Breiman L, Friedman JH, Olshen RA \& Stone CJ (1984) Classification and Regression Trees, pp. 134-158. Monterey, CA: Wadsworth and Brooks-Cole.

Chen DC, Nommsen-Rivers L, Dewey KG \& Lönnerdal B (1998) Stress during labor and delivery and early lactation performance. Am J Clin Nutr 68, 335-344.

Clarke AJ \& Sibert JR (1985) Hypernatraemic dehydration and necrotizing enterocolitis. Postgrad Med J 61, 65-66.

Cooper WO, Atherton HD, Kahana M \& Kotagal UR (1995) Increased incidence of severe breastfeeding malnutrition in a metropolitan area. Pediatrics 96, 957-960.
Dewey KG, Nommse-Rivers LA, Heinig J \& Cohen RJ (2003) Risk factors for suboptimal infant breastfeeding behaviour, delayed onset of lactation, and excess neonatal weight loss. Pediatrics 112, 607-619.

Evans KC, Evans RG, Royal R, Esterman AJ \& James SL (2003) Effect of caesarean section on breast milk transfer to the normal term newborn over the first week of life. Arch Dis Child Fetal Neonatal Ed 88, F380.

Hartmann P \& Cregan M (2001) Lactogenesis and the effects of insulin-dependent diabetes mellitus and prematurity. J Nutr 131, 3016S-3020S.

Kumral A, Duman N, Tatli MM, Ozbek A, Demircioglu F \& Ozkan H (2002) Hypernatraemic dehydration due to high sodium concentrations in breast milk: possible relationship with unwanted pregnancy. Acta Paediatr 91, 1268-1269.

Livingstone VH, Willis CE, Abdel-Wareth LO, Thiessen P \& Lockitch G (2000) Neonatal hypernatremic dehydration associated with breast-feeding malnutrition: a retrospective survey. CMAJ 162, 647-660.

McCullagh P \& Nelder JA (1999) Generalized Linear Model, pp. 21-40. New York: Chapman \& Hall/CRC.

Manganaro R, Mamì C, Marrone T, Marseglia L \& Gemelli M (2001) Incidence of dehydration and hypernatremia in exclusively breastfed infants. J Pediatr 139, 673-675.

Neville MC (1987) Measurement of milk transfer from mother to breastfeeding infant. J Pediatr Gastroenetrol Nutr 6, 659-662.

Neville MC, Allen JC, Archer P, Casey CE, Seacat J, Kellea RP, Lutes S, Rasbach J \& Neifert M (1991) Studies in human lactation: milk volume and nutrient composition during weaning and lactogenesis. Am J Clin Nutr 54, 81-92.

Neville MC \& Morton JA (2001) Physiology and endocrine changes underlying human lactogenesis II. J Nutr 131, 3005S-3008S.

Neville MC, Morton JA \& Umemura S (2001) Lactogenesis. The transition from pregnancy to lactation. Pediatr Clin North Am 48, 35-52.

Nguyen DA \& Neville MC (1998) Tight junction regulation in the mammary gland. J Mammary Gland Biol Neoplasia 3, 233-246.

Oddie S, Richmond S \& Coulthard M (2001) Hypernatraemic dehydration and breast feeding: a population study. Arch Dis Child 85, 318-320.

Peters JM (1989) Hypernatremia in breast-fed infants due to elevated breast milk sodium. J Ant Osteopath Assoc 89, 1165-1170.

Rand SE \& Kolberg A (2001) Neonatal hypernatremic dehydration secondary to lactation failure. J Am Board Fam Pract 14, 155-158.

Richmond S (2003) Hypernatraemic dehydration: excess sodium is not the cause. Arch Dis Child Fetal Neonatal Ed 88, F349-F352.

Rowland TW, Zori RT, Lafleur WR \& Reiter EO (1982) Malnutrition and hypernatremic dehydration in breastfed infants. JAMA 247, 1016-1017. 